\title{
Osteoblastoma of the Carpal Scaphoid: A Case Report
}

\author{
Mohamed Rida El Galiou*, Houass EY, Boufettal M, Bassir RA, Kharmaz M, Lamrani MO, Berrada MS
}

Department of Orthopedics and Traumatology, University Hospital Center of Rabat, Faculty of Medicine and Pharmacy of Rabat, University

Mohammed V Souissi, Rabat, 10000, Morocco

DOI: $10.36347 /$ sjams.2020.v08i11.032

| Received: 09.11.2020 | Accepted: 20.11.2020 | Published: 23.11.2020

*Corresponding author: Mohamed Rida El Galiou

\section{Abstract}

Osteoblastoma is a rare tumor. This is a rare tumor in the carpal bones, only nine cases have been reported in the literature. It is a benign but potentially aggressive tumor, its radioclinic translation is not very specific and its diagnosis is histological. We report the case of carpal scaphoid osteoblastoma in a 17-year-old patient revealed by localized pain and partial functional impotence, and confirmed histologically. Our patient underwent first row resection due to the aggressive nature of the tumor.

Keywords: Osteoblastoma, tumor, carpal scaphoid.

Copyright $\odot 2020$ The Author(s): This is an open-access article distributed under the terms of the Creative Commons Attribution 4.0 International License (CC BY-NC 4.0) which permits unrestricted use, distribution, and reproduction in any medium for non-commercial use provided the original author and source are credited.

\section{INTRODUCTION}

Osteoblastoma is an entity individualized by Jaffe el Lichtenstein as a benign bone tumor of osteoblastic origin characterized by the proliferation of numerous osteoblasts and the presence of a large amount of osteoid tissue within a richly vascularized connective stroma [1]. Osteoblastoma is a rare bone tumor, occurring in the second and third decade with a clear male predominance, preferentially located in the spine, followed by the long bones of the limbs and more rarely the extremities [2]. We report an observation of an osteoblastoma located in the carpal scaphoid.

\section{Clinical Observation}

This was a 17-year-old patient, right-handed, who presented to the consultation for progressive pain in the right wrist with no particular rhythm, associated with a swelling gradually increasing in size, all evolving over the past year. During this period, the patient had benefited from multiple symptomatic treatments combining analgesics, non-steroidal anti-inflammatory drugs and periods of immobilization by wrist braces, but without improvement. The symptoms had become permanent for the past two months. On examination, there was a firm, tender, poorly defined swelling on the radial edge of the wrist. The wrist was stiff and sore. The laboratory tests were all normal. X-ray of the right wrist showed a rounded bony void covering the entire scaphoid, with cortical swelling and anterior development (Fig. 1). Magnetic resonance imaging revealed the presence of an externally lateralized carpal process measuring $27 \times 30 \times 30 \mathrm{~mm}$ largely at the expense of the scaphoid which is lysed, pushing back the tendon structures which remain continuous (fig. 2). This process is distinguished by aT1 hyposignal and T2hypersignalenhanced by gadolinium with a heterogeneous signal. We opted for a first biopsy, by an anterior approach (fig. 3). After histological confirmation of the diagnosis and given the aggressive nature of the lesion, a resection of the first row was performed with immobilization in a cast (fig. 4). After 2 years of follow-up, the patient described episodic pain at the end of the day. Wrist mobilities were $30^{\circ}$ of flexion and $40^{\circ}$ of extension and complete pronosupination; the mobility of the long fingers and thumb was normal.

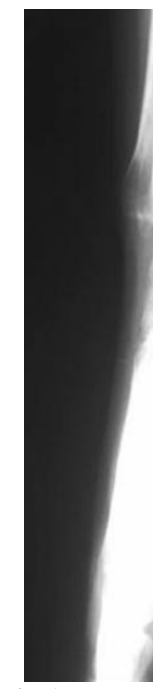

Fig-1: X-ray of the right wrist, face and profile showing the scaphoid bone gap 


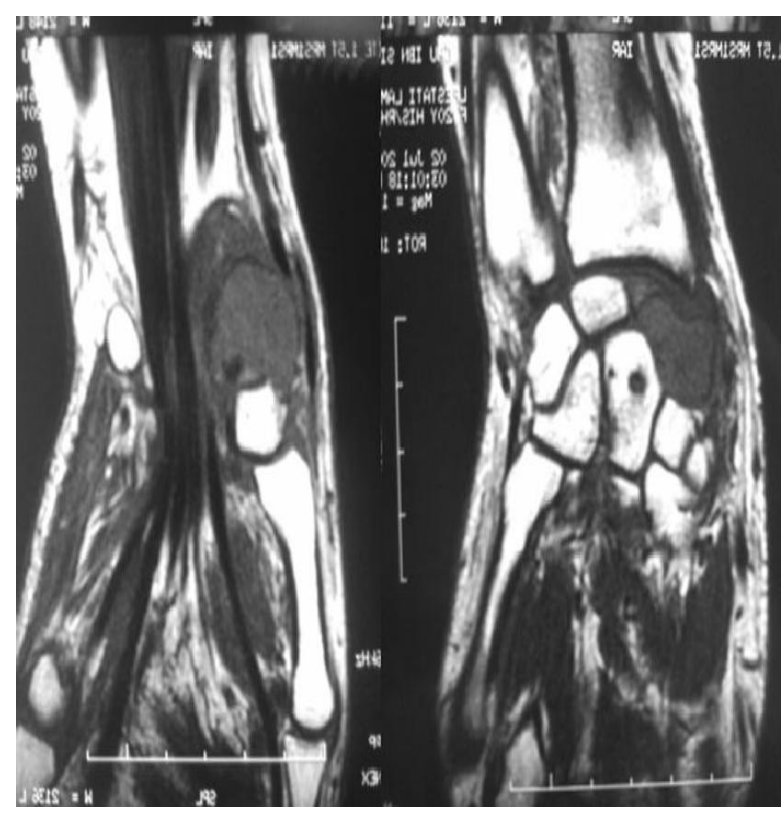

Fig-2: MRI sections showing the presence of a carpal process at the expense of the lysed scaphoid

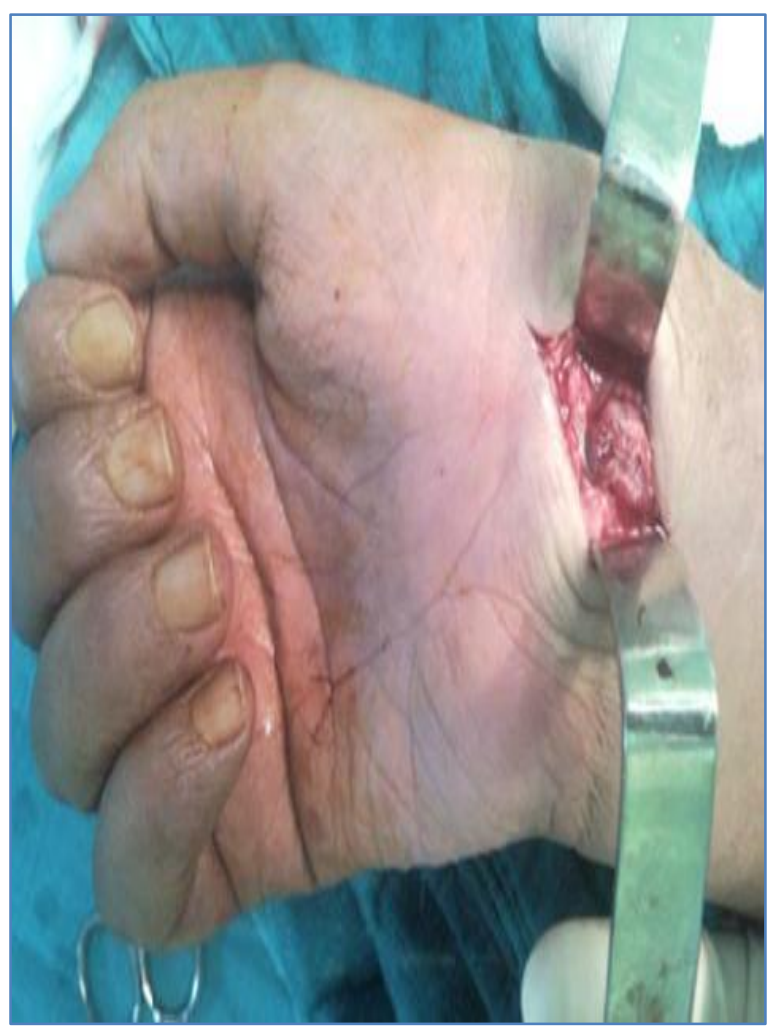

Fig-3: Intraoperative view showing the anterior approach to the biopsy

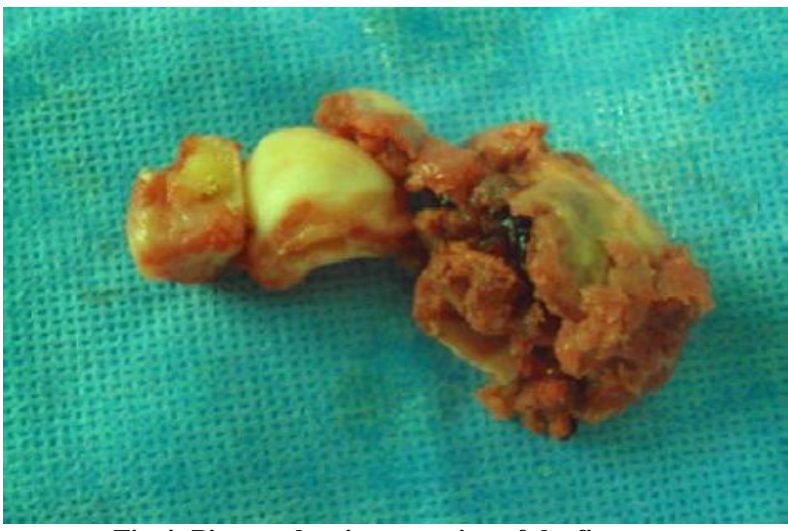

Fig-4: Picture showing resection of the first row

\section{DISCUSSION}

Osteoblastoma is a benign but locally aggressive tumor, representing $1 \%$ of all primary bone tumors $[3,4]$. It is a particularly rare tumor in the carpal bones; we only found six cases of scaphoid osteoblastoma reported in isolation in the literature. This tumor typically occurs between ten and 25 years old, and is twice as common in men [5]. When faced with a tumor of this type, in the absence of specific clinical and radiological signs, it is quite certain that a histological examination for diagnostic purposes is necessary [6]. Indeed, before the biopsy, several differential diagnoses can be evoked, giant cell tumor, aneurysmal cyst, chondrosarcoma, or even osteosarcoma [7]. The distinctive criteria between osteoblastoma and osteoid osteoma are mainly macroscopic (size greater than $2 \mathrm{~cm}$ ) and progressive. On a microscopic level, the lesional appearance is sometimes strictly superimposed on that of an osteoid osteoma. Osteoblastoma is a benign tumor, but with a significant risk of recurrence and malignant degeneration [8]. Some authors, considering that the recurrence rates (10 to $19 \%$ ) after intra-lesional surgery is relatively important, suggest systematic wide resection even for carpal locations [4, 9]. However, these large resections at the carpal level could generate significant functional consequences. The treatment of carpal osteoblastomas must be conservative in priority; radical actions must be reserved for recurrences but can also be discussed in the face of these so-called aggressive forms [5].

\section{CONCLUSION}

The carpal sites of osteoblastomas are rare. Their diagnosis is difficult due to the absence of specific clinical and radiological signs. An algodystrophic syndrome is a possible mode of revelation. Curettage of the lesion appears sufficient in slowly evolving lesions. Hence the importance of distinguishing, among these benign tumors, the aggressive forms which may immediately lead to the opting for a radical action. 


\section{REFERENCE}

1. Jaffe HL. Benign osteoblasma. Bull Hosp Joint Dis.1956 Oct; 17(2):141-51.

2. M, Cognet JM, Chiffolot X. Ostéoblastomeépiphysaire tibial: une localisation inhabituelle: à propos d'un cas et revue de la littérature. Rev ChirOrthopReparatrice Appar Mot. 2003 May; 89(3):266-71. In press

3. Fanning JW, Lucas GL. Osteoblastoma of the scaphoid: a case report. J Hand Surg (Am). 1993;18(4):663-5.

4. Lucas DR, Unni KK, McLeod RA, O’Connor M, Sim FH. Osteoblastoma: clinicopathologic study of 306 cases. Hum Pathol. 1994;25:117-34.

5. Gdoura F, Trigui M, Ellouze Z, Hamed YB, Ayadi K, Keskes H. Ostéoblastome de l'hamatum. Revue de chirurgie orthopédique et traumatologique. 2010 Oct 1;96(6):775-9.
6. Azouz M, Rhanim A, Rotbi M, Karabila MA MhaMDI Y, Kharmaz M, Ismail F, Bardouni A, Mahfoud M, Berrada MS, Elyaacoub M. Ostéoblastome du scaphoïde carpien. À propos d'un cas clinique. Chirurgie de la main. 2013;6(32):483.

7. Ragois P, Leclerc P, Hallonet D. Aggressive osteoblastoma of the carpal scaphoid bone. Rev ChirOrthop. 2000;86(1):94-7.

8. Dorfman HD, Weiss SW. Borderline osteoblastic tumors: 8 problems in the differential diagnosis of agressiveosteoblastoma and low-grade osteosarcoma. SeminDiagnPathol. 1984;1:215-34.

9. Van Dijk M, Winters HA, Wuisman PI. Recurrent osteoblastoma of the hamate bone. A two-stage reconstruction with a free vascularized iliac crest flap. J Hand Surg (Br). 1999;24(4):501-5. 